\title{
A Study on the Direction of Inscription of the Vectorcardiographic T-Loop in Left and Right Ventricular Hypertrophy
}

\author{
Kenichi Harumi, M.D., Saburo Mashima, M.D., \\ Chuichi Sato, M.D., Yoshimi YanaI, M.D., \\ and Hideo UEDA, M.D.
}

The vectorcardiographic loop was classified into 8 types according to the direction of inscription in 3 planar projections. Types of the T-loop were examined with the spatial orientation of it and some characteristic types observed in left and right ventricular hypertrophy were described. The concept of the polar vector was used in expressing types of the loop and in studying geometrical properties of it.

T $\mathrm{N}$ the study of vetorcardiography, the direction of inscription of the vector loop constitutes an important information which is difficult to be obtained by other method. While the direction of inscription of the QRS-loop has been studied by many investigators, relatively few reports ${ }^{1)-4)}$ have appeared concerning that of the T-loop.

The following report includes our observations on the direction of inscription of the T-loop and on the spatial orientation of it in various conditions. The concept of the polar vector was used in studying the geometrical properties of the loop. Some observations were made also on the QRS-loop.

\section{Materials and Methods}

A total of 353 cases examined, include 30 normal and 151 hypertensive cases, and 172 cases with acquired or congenital heart disease. Hypertensive cases were divided into 2 groups according to absence or presence of cardiac complaints: group I of 108 cases were free from them and group II of 43 cases had complaints such as anginal attacks or marked extracardiac signs of congestive heart failure. Acquired valvular disease includes aortic valvular disease (19 cases), mitral stenosis (31 cases) and mitral stenosis and regurgitation or combined aortic and mitral lesions (70 cases). Cases with congenital heart disease consist of 30 cases with atrial septal defect of ostium secundum type, 7 cases with pulmonary stenosis and 15 cases with trilogy, tetralogy or pentalogy of Fallot. In majority of cases with congenital heart disease, the diagnosis was confirmed by cardiac

From the Second Department of Intermal Medicine, Faculty of Medicine, University of Tokyo, Tokyo. 
catheterization. Cases with definite evidences of bundle branch block or myocardial infarction were excluded from the study group.

In all cases, frontal, horizontal and right sagittal projections of spatial vectorcardiogram were recorded with the Frank lead system. In each plane, the directions of inscription of the T-and the QRS-loops were determined to be clockwise or counterclockwise. Figure-of-eight configuration was considered

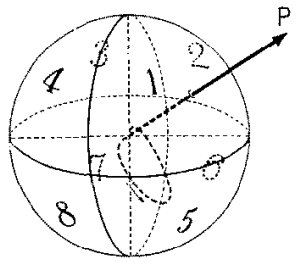

Fig. 1. Vector loop and its polar vector. An arrow $P$ indicates the polar vector of the loop at the origin. The table shows the relationship between the direction of the polar vector and the direction of inscription of the vector loop in 3 planar projections.

\begin{tabular}{|c|c|c|c|c|}
\hline \multirow{2}{*}{ type } & \multirow{2}{*}{ direction of the polar vector } & \multicolumn{3}{|c|}{$\begin{array}{c}\text { direction of inscription } \\
\text { of the T-loop }\end{array}$} \\
\hline & & frontal & $\begin{array}{l}\text { hori- } \\
\text { zontal }\end{array}$ & $\begin{array}{c}\text { right } \\
\text { sagittal }\end{array}$ \\
\hline 1 & left, anterior, superior & cc. & cc. & c. \\
\hline 2 & left, posterior, superior & c. & cc. & c. \\
\hline 3 & right, posterior, superior & c. & $\mathrm{cc}$. & cc. \\
\hline 4 & right, anterior, superior & cc. & $c c$. & cc. \\
\hline 5 & left, anterior, inferior & cc. & c. & c. \\
\hline 6 & left, posterior, inferior & $c$ & c. & c. \\
\hline 7 & right, posterior, inferior & c. & c. & cc. \\
\hline 8 & right, anterior, inferior & cc. & c. & cc. \\
\hline
\end{tabular}

to have the direction of inscription of the part enclosing larger area. The combination of the directions of inscription makes 8 types of the loop (Fig. 1). In some cases, the direction of inscription could not be determined, for their loops were club-like in shape enclosing no area or efferent and afferent limbs of the loop crossed to form 2 loops of equal area. When the direction of inscription was not determined at least in one plane, the type of that loop was "undetermined."

Polar Vector: On the basis of the fact that the vector loop in many cases lies on one plane, a vector characterizing the loop named polar vector is defined by Burger ${ }^{5}$ as follows: the direction of the polar vector is perpendicular to the plane in which the loop exists, the magnitude of the polar vector is proportional to the area enclosed by the loop and the polar vector should be drawn at the side in which the direction of inscription of the loop was counterclockwise. Consequently, a given octant in space, to which the polar vector is directed, determines the direction of inscription of the loop in 3 planar projections (Fig. 1). In Fig. 1, it is shown that 8 types of the vector loop are equivalent to 8 octants to which the polar vector of that loop is directed. When the loop was club-like in one plane, the polar vector of it is on the border line of 2 octants. For instance, when the loop is club-like in frontal, counterclockwise in horizontal and clockwise in sagittal planes, it is of intermediate type between types 1 and 2. The polar vector of this loop is on the line (or plane) bordering octants 1 and 2. This loop is described as type 1-2.

In addition to these classifications, spatial orientation of the T-loop was described by the maximal vector and that of the QRS-loop by half area vector by Pipberger. ${ }^{6}$ 


\section{Results}

Distribution of all cases to types of the T-loop is shown in Table I. In normal cases, only types 1 and 2 were seen, that is, the T-loop was inscribed counterclockwise in horizontal and clockwise in right sagittal

Table I. Number of Cases with 8 Types of the TLoop in Various Cionditions

\begin{tabular}{c|c|c|c|c|c|c|c|c|c|c}
\hline $\begin{array}{c}\text { type } \\
\text { condition }\end{array}$ & 1 & 2 & 3 & 4 & 5 & 6 & 7 & 8 & $\begin{array}{c}\text { undeter } \\
\text { mined }\end{array}$ & total \\
\hline normal & 3 & 17 & 0 & 0 & 0 & 0 & 0 & 0 & 10 & 30 \\
\hline hypertension I & 27 & 31 & 0 & 1 & 11 & 7 & 3 & 0 & 28 & 108 \\
\hline $\begin{array}{c}\text { hypertension II } \\
\text { aortic valvular } \\
\text { disease }\end{array}$ & 8 & 6 & 0 & 2 & 8 & 4 & 3 & 1 & 11 & 43 \\
\hline \begin{tabular}{c} 
mitral stenosis \\
\hline $\begin{array}{c}\text { other acquired } \\
\text { valvular diseases }\end{array}$
\end{tabular} & 6 & 16 & 6 & 1 & 1 & 6 & 13 & 1 & 20 & 70 \\
\hline $\begin{array}{c}\text { atrial septal } \\
\text { defect }\end{array}$ & 0 & 2 & 0 & 0 & 0 & 2 & 19 & 1 & 6 & 30 \\
\hline $\begin{array}{c}\text { pulmonary steno- } \\
\text { sis and Fallot }\end{array}$ & 0 & 0 & 2 & 0 & 0 & 3 & 11 & 0 & 6 & 2 \\
\hline
\end{tabular}

planes. In 4 of 10 undetermined cases, the T-loop was of type 1-2 (clublike in frontal plane). In other 6 cases, the T-loop was of type 2-6 in 2 , of type $2-3$ in one case and in the remaining 3 it was club-like in 2 planes.

In hypertension group I, there were 21 cases of abnormal types 5, 6 and 7 . They are characterized by abnormal clockwise inscription in horizontal plane and in 3 cases of type 7, in addition, by counterclockwise inscription in right sagittal plane. In hypertension group II, similar inscription types were seen as in hypertension group I, but the percentage of abnormal cases was higher. In aortic valvular disease, 3 cases of type 3 were observed, that is, the T-loop was inscribed counterclockwise in sagittal plane and normally (counterclockwise) in horizontal plane.

In mitral stenosis, normal type 2 and abnormal types 3 and 7 were predominant and in 6 of 14 undetermined cases, the T-loop was of type 
2-6. In congenital heart disease, the T-loop of abnormal types 6 and 7 were observed in most of the cases.

In Table II, similar observations on the QRS-loop are shown. In

Table II. Number of Cases with 8 Types of the QRS-

Loop in Various Conditions

\begin{tabular}{|c|c|c|c|c|c|c|c|c|c|c|}
\hline condition type & 1 & 2 & 3 & 4 & 5 & 6 & 7 & 8 & $\begin{array}{l}\text { undeter- } \\
\text { mined }\end{array}$ & total \\
\hline normal & 10 & 18 & 0 & 0 & 0 & 0 & 0 & 0 & 2 & 30 \\
\hline hypertension I & 37 & 61 & 1 & 0 & 1 & 1 & 0 & 0 & 7 & 108 \\
\hline hypertension II & 15 & 23 & 1 & 0 & 0 & 1 & 0 & 0 & 3 & 43 \\
\hline $\begin{array}{c}\text { aortic valvular } \\
\text { disease }\end{array}$ & 9 & 5 & 2 & 0 & 2 & 0 & 1 & 0 & 0 & 19 \\
\hline mitral stenosis & 6 & 20 & 1 & 0 & 0 & 4 & 0 & 0 & 0 & 31 \\
\hline $\begin{array}{l}\text { other acquired } \\
\text { valvular diseases }\end{array}$ & 16 & 33 & 4 & 0 & 3 & 3 & 2 & 0 & 9 & 70 \\
\hline $\begin{array}{l}\text { atrial septal } \\
\text { defect }\end{array}$ & 0 & 10 & 2 & 0 & 1 & 8 & 6 & 0 & 3 & 30 \\
\hline $\begin{array}{l}\text { pulmonary steno- } \\
\text { sis and Fallot }\end{array}$ & 0 & 4 & 0 & 0 & 0 & 9 & 7 & 0 & 2 & 22 \\
\hline
\end{tabular}

this table, it can be seen that normal inscription types 1 and 2 are predominant in various conditions but there are some cases of types 3 and 5 in aortic valvular disease, those of type 6 in mitral stenosis and those of types 3,6 and 7 in congenital heart disease. Abnormal inscription of the QRS-loop was observed less frequently in left than in right ventricular hypertrophy. Comparing right ventricular hypertrophy due to mitral stenosis and to congenital heart disease, counterclockwise inscription of the QRS-loop in right sagittal plane was observed rarely in the former and commonly in the latter.

Hypertension: Normal and abnormal types of the T-loop frequently seen in hypertension group I, were examined with the spatial orientation of the T-loop. Results are shown in Fig. 2. Cases of normal inscription (types 1 and 2) were plotted in the most outside of concentric circular bands and compared with those of abnormal inscription in inner bands. In frontal plane, gradual increase in the rightward deviation of the $\mathrm{T}$ axis occurred from types 1 and 2 to types 5 and 6 in this order. In 3 cases of type 7, the T-loop was oriented right and superiorly. In hori- 


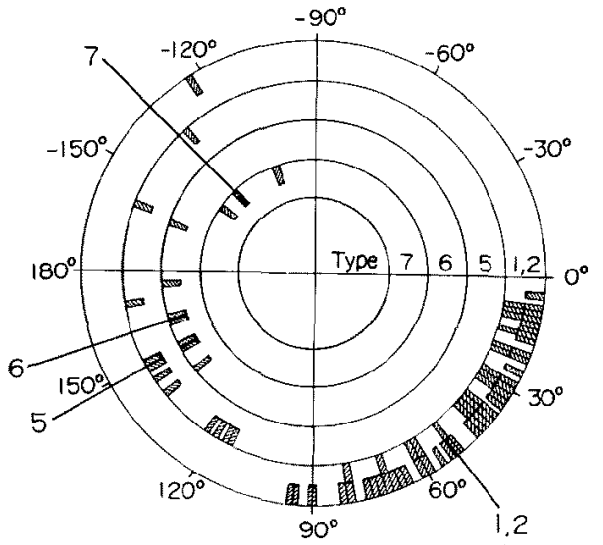

Frontal

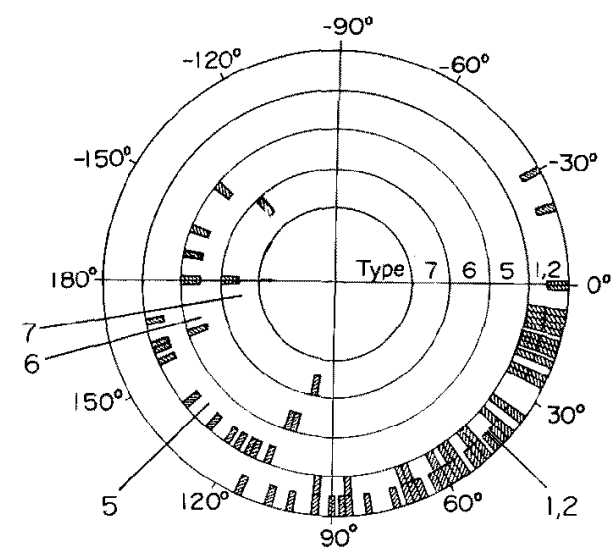

Horizontal

Fig. 2. Direction of the T-loop of various types in cases with hypertension (group I). Maximal vector of the loop of types $1,2,5,6$ and 7 is shown in frontal and horizontal planes. Long line indicates average direction in each type.

zontal plane, similar tendency was observed but there was no remarkable difference between types 6 and 7 . No cases of normal types ( 1 and 2) had the T-loop directed rightward more than $120^{\circ}$ in horizontal plane and there seemed to be a critical direction of $100^{\circ} \sim 120^{\circ}$ which separated normal and abnormal types. The average directions of the $\mathrm{T}$ - and the QRS-loop and their ranges are in Table III. Types were concerning the

Table III. Directions of the T- and the QRS-Loop in Cases with Hypertension Group I

\begin{tabular}{|c|c|c|c|c|c|c|}
\hline \multicolumn{3}{|c|}{ type } & $1-2$ & 5 & 6 & 7 \\
\hline \multicolumn{3}{|c|}{ number of cases } & 58 & 11 & 7 & 3 \\
\hline \multirow{4}{*}{$\mathrm{T}$} & \multirow{2}{*}{ frontal } & average & $51^{\circ}$ & $149^{\circ}$ & $162^{\circ}$ & $-137^{\circ}$ \\
\hline & & range & $66^{\circ} \sim-123^{\circ}$ & $115^{\circ} \sim-133^{\circ}$ & $141^{\circ} \sim-162^{\circ}$ & $-166^{\circ} \sim-110^{\circ}$ \\
\hline & \multirow{2}{*}{ horizontal } & average & $43^{\circ}$ & $135^{\circ}$ & $166^{\circ}$ & $169^{\circ}$ \\
\hline & & range & $-30^{\circ} \sim 113^{\circ}$ & $110^{\circ} \sim 167^{\circ}$ & $105^{\circ} \sim-142^{\circ}$ & $101^{\circ} \sim-133^{\circ}$ \\
\hline \multirow{4}{*}{ QRS } & \multirow{2}{*}{$\begin{array}{c}\text { frontal } \\
\vdots\end{array}$} & average & $31^{\circ}$ & $26^{\circ}$ & $24^{\circ}$ & $31^{\circ}$ \\
\hline & & range & $-25^{\circ} \sim 98^{\circ}$ & $7^{\circ} \sim 50^{\circ}$ & $0^{\circ} \sim 34^{\circ}$ & $-7^{\circ} \sim 70^{\circ}$ \\
\hline & \multirow{2}{*}{ horizontal } & average & $-19^{\circ}$ & $-21^{\circ}$ & $-12^{\circ}$ & $-7^{\circ}$ \\
\hline & & range & $-171^{\circ} \sim 47^{\circ}$ & $-63^{\circ} \sim-5^{\circ}$ & $-34^{\circ} \sim 10^{\circ}$ & $-33^{\circ} \sim 26^{\circ}$ \\
\hline
\end{tabular}

Type number chracterizes the direction of inscription of the T-loop.

T-loop inscription and there was no definite difference in the QRS direction between these types. 
Similar observations were made on the cases of hypertension with cardiac complaints (hypertension group II) and the results were in Fig. 3. In this figure, 3 undetermined cases of type 1-2 were plotted together

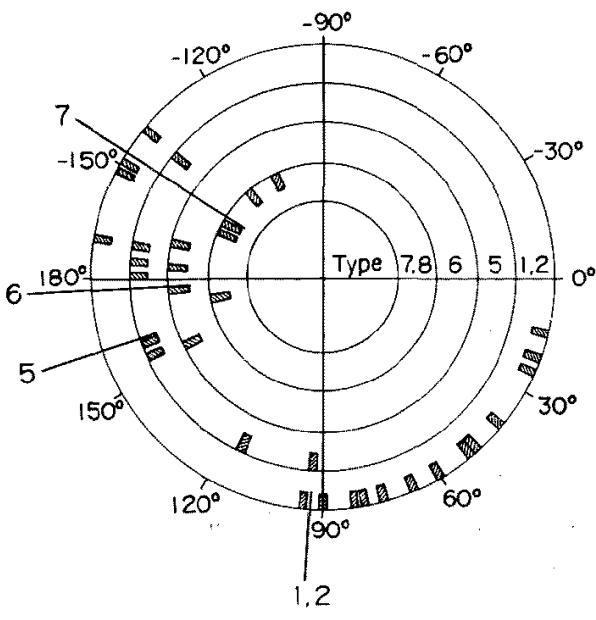

Frontal

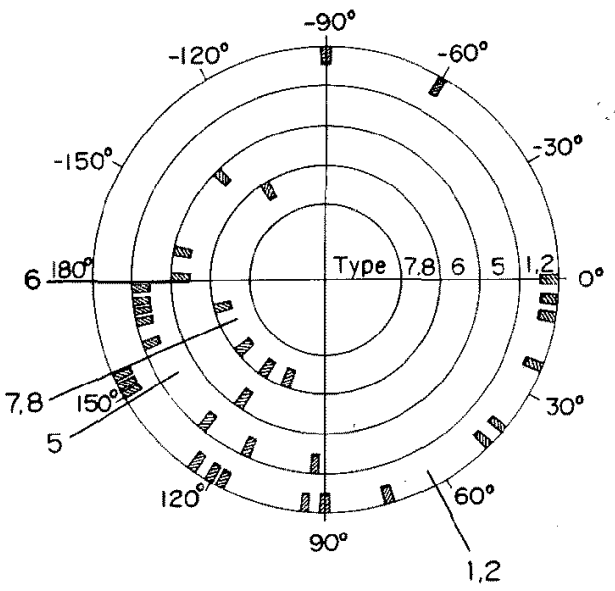

Horizontal

Fig. 3. Direction of the T-loop of various types in cases with hypertension (group II). Maximal vector of the loop of types $1,2,5,6,7$ and 8 is shown in frontal and horizontal planes. Long line indicates average direction in each type.

with types 1 and 2 and one case of type 8 and one undetermined case of type 7-8 were plotted together with type 7 .

The T-loop of types 1 and 2 in this condition was more widely distributed than in hypertension group I. Cases in which the T-loop of

Table IV. Directions of the T- and the QRS-Loop in Cases with Hypertension Group II

\begin{tabular}{|c|c|c|c|c|c|c|}
\hline \multicolumn{3}{|c|}{ type } & $1-2$ & 5 & 6 & $7-8$ \\
\hline \multicolumn{3}{|c|}{ number of cases } & 17 & 8 & 4 & 5 \\
\hline \multirow{4}{*}{$\mathrm{T}$} & \multirow{2}{*}{ frontal } & average & $93^{\circ}$ & $63^{\circ}$ & $177^{\circ}$ & $-147^{\circ}$ \\
\hline & & range & $14^{\circ} \sim-139^{\circ}$ & $93^{\circ} \sim-140^{\circ}$ & $154^{\circ} \sim-167^{\circ}$ & $170^{\circ} \sim-113^{\circ}$ \\
\hline & \multirow{2}{*}{ horizontal } & average & $62^{\circ}$ & $148^{\circ}$ & $180^{\circ}$ & $156^{\circ}$ \\
\hline & & range & $-90^{\circ} \sim 155^{\circ}$ & $92^{\circ} \sim 177^{\circ}$ & $125^{\circ} \sim-134^{\circ}$ & $110^{\circ} \sim-122^{\circ}$ \\
\hline \multirow{4}{*}{ QRS } & \multirow{2}{*}{ frontal } & average & $30^{\circ}$ & $23^{\circ}$ & $26^{\circ}$ & $51^{\circ}$ \\
\hline & & range & $0^{\circ} \sim 146^{\circ}$ & $12^{\circ} \sim 35^{\circ}$ & $20^{\circ} \sim 37^{\circ}$ & $30^{\circ} \sim 78^{\circ}$ \\
\hline & \multirow{2}{*}{ horizontal } & average & $\sim 21^{\circ}$ & $-26^{\circ}$ & $-17^{\circ}$ & $-40^{\circ}$ \\
\hline & & range & $-88^{\circ} \sim 10^{\circ}$ & $-48^{\circ} \sim-6^{\circ}$ & $-34^{\circ} \sim-2^{\circ}$ & $-83^{\circ} \sim-14^{\circ}$ \\
\hline
\end{tabular}

Type number characterizes the direction of inscription of the T-loop. 


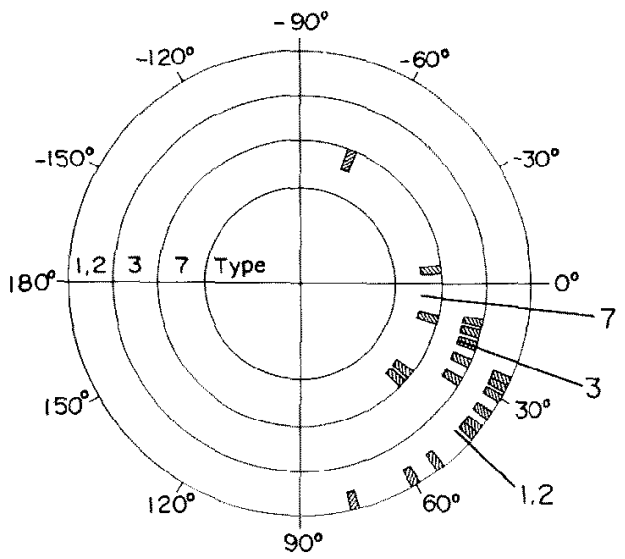

Frontal

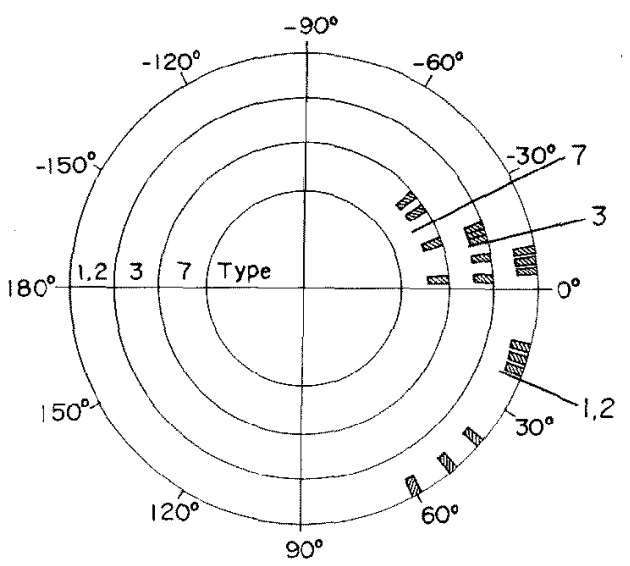

Horizontal

Fig. 4. Direction of the T-loop of various types in cases with mitral stenosis. Maximal vector of the loop of types 1,2, 3 and 7 is shown in frontal and horizontal planes. Long line indicates average direction in each type.

normal type was directed $-90^{\circ}$ or more than $150^{\circ}$ in horizontal plane, were observed in Fig. 3. Clinically, all cases with the T-loop of normal type and directed $-90^{\circ}$ or more than $150^{\circ}$ in horizontal plane had anginal attacks. Average directions of the $\mathrm{T}$ - and the QRS-loop and their ranges are in Table IV.

Aortic Valvular Disease: In this condition, 3 cases with the T-loop of type 3 were observed. These loops were oriented anteriorly, left and superiorly in 2 cases and anteriorly, right and slightly inferiorly in one. The T-loops of other types were directed similarly as those of corresponding types in hypertension except that some loops of normal type showed inferior and more posterior direction than in hypertensive cases. They were accompanied by marked posteriorly oriented QRS-loop.

Mitral Stenosis: In Fig. 4, relation of the inscription and the direction of the T-loop is shown. Although there were not sufficient number of cases in each type, there appeared increasing backward displacement of the T-loop in normal type, type 3 and type 7 in this order. In frontal plane, left axis deviation of the $\mathrm{T}$ vector of normal type seemed less marked than that of abnormal type. Directions of the QRS-loops are in Table V. There were definite difference in the QRS direction between normal and abnormal types but the difference between type 3 and type 7 was not clear. In cases with mitral stenosis, types of the Tloop inscription were compared with those of the QRS inscription (Table VI). It is clear that when the T-loop was inscribed normally, the QRSloop was also inscribed normally and abnormal inscription of the QRSloop was always accompanied by abnormal inscription of the T-loop. 
Table V. Directions of the T-and the QRS-Loops in Cases with Mitral Stenosis

\begin{tabular}{|c|c|c|c|c|c|}
\hline \multicolumn{3}{|c|}{ type } & $1-2$ & 3 & 7 \\
\hline \multicolumn{3}{|c|}{ number of cases } & 9 & 5 & 5 \\
\hline \multirow{4}{*}{$\mathrm{T}$} & \multirow{2}{*}{ frontal } & average & $43^{\circ}$ & $21^{\circ}$ & $5^{\circ}$ \\
\hline & & range & $25^{\circ} \sim 76^{\circ}$ & $13^{\circ} \sim 32^{\circ}$ & $-68^{\circ} \sim 45^{\circ}$ \\
\hline & \multirow{2}{*}{ horizontal } & average & $22^{\circ}$ & $-14^{\circ}$ & $-28^{\circ}$ \\
\hline & & range & $-8^{\circ} \sim 60^{\circ}$ & $-20^{\circ} \sim-3^{\circ}$ & $-40^{\circ} \sim-4^{\circ}$ \\
\hline \multirow{4}{*}{ QRS } & \multirow{2}{*}{ frontal } & average & $50^{\circ}$ & $94^{\circ}$ & $89^{\circ}$ \\
\hline & & range & $19^{\circ} \sim 74^{\circ}$ & $61^{\circ} \sim 142^{\circ}$ & $16^{\circ} \sim 130^{\circ}$ \\
\hline & \multirow{2}{*}{ horizontal } & average & $-8^{\circ}$ & $63^{\circ}$ & $58^{\circ}$ \\
\hline & & range & $-42^{\circ} \sim 10^{\circ}$ & $0^{\circ} \sim 174^{\circ}$ & $8^{\circ}-137^{\circ}$ \\
\hline
\end{tabular}

Type number characterizes the direction of inscription of the T-loop.

Table VI. Relation of the Inscription of the T-Loop to That of the QRS-Loop in Cases with Mitral Stenosis

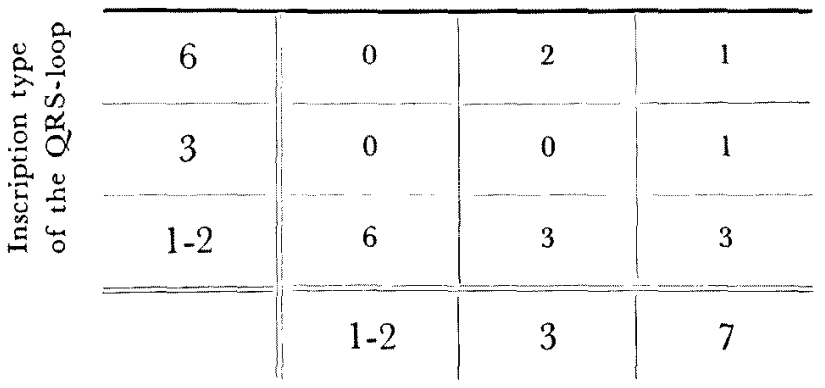

Inscription type of the $\mathrm{T}$-loop

In 3 cases of type 3 and in 3 cases of type 7, systolic pressure in the right ventricle was determined by cardiac catheterization. Their values were 83,54 and $39 \mathrm{~mm} . \mathrm{Hg}$ in cases of type 3 and 130,72 and $44 \mathrm{~mm} . \mathrm{Hg}$ in cases of type 7.

Congenital Heart Disease: The T-loops of types 6 and 7 were commonly seen in this condition. In cases of type 7, the T-loop was directed left posteriorly and inferiorly in most cases, and in some cases it was directed left anteriorly and inferiorly or superiorly. Average directions were $28^{\circ}$ in frontal and $-7^{\circ}$ in horizontal defect and $19^{\circ}$ in frontal and $-29^{\circ}$ in horizontal planes in pulmonary stenosis and in tetralogy or pentalogy of Fallot. The normal inscription of the $\mathrm{T}$ loop was observed in 2 cases with atrial septal defect, and in both cases the QRS-loop was also inscribed normally. 


\section{Discussion}

\section{Polar Vector and Its Relation to the Maximal Vector :-}

The concept of polar vector is based on the assumption that the vector loop lies on one plane. Since the configuration of the T-loop is relatively simple, the assumption appears more adequate than with the QRS-loop. Moreover, the T-loop is narrow and elliptical in shape, so that the polar vector and the maximal vector, consequently inscription and orientation of the loop are, to some extent, related, as expressed by the following rule of exclusion: when the loop is planar, narrow and elliptical in shape, the polar vector and the maximal axis of the loop is directed neither in the same, nor in the directly opposite octants in space. For instance, when the maximal $\mathrm{T}$ vector is in the left, anterior and inferior direction, its polar vector is directed neither in octant 3 , nor in the octant 5 (Fig. 5, C), that is, the T-loop inscriptions of the type "clockwise in

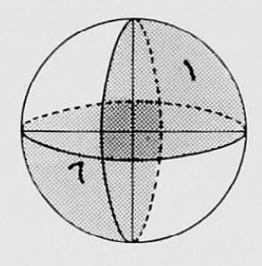

A

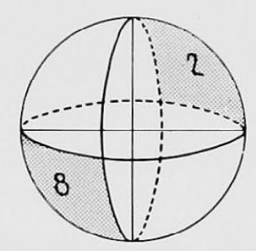

B

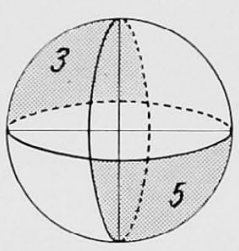

C

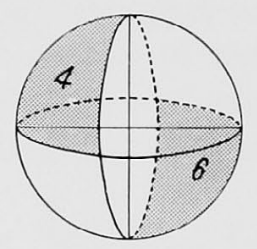

D

Fig. 5. The surface of the sphere in 2 octants of directly opposite direction. Since the maximal $\mathrm{T}$ vector and the polar vector are perpendicular each other, these 2 vectors is neither in the same, nor in the opposite octant (see text and Fig. 1).

frontal, counterclockwise in horizontal and counterclockwise in sagittal planes" and of the type "counterclockwise in frontal, clockwise in horizontal, and clockwise in sagittal planes" are both excluded (Fig. 1). When the loop is complicated in shape or it occupies several octants, this rule is not always correct. But in all of our cases, the T-loop satisfied the requirement of this rule. The rule does not imply that one of these 2 vectors is uniquely determined for a given direction of the other. Only 2 out of 8 octants are excluded and arbiturary directions are allowed in the remaining 6 octants. Another point that requires comment, is occurrence of the ST vector. The ST vector is usually small compared with the maximal QRS or $\mathrm{T}$ vector and it was neglected in examining the direction of inscription of the T-loop in this study. When the ST vector is sufficiently great, so that the QRS- and T-loop are widely open and the direction of inscription of the T-loop may be obscured, the case must be 
abandoned for analysis.

Left Ventricular Hypertrophy :-

There have been previous observations by several investigators. Kimura ${ }^{1)}$ reported changes in the direction of inscription of the T-loop in cases with restricted cardiac function. Portheine ${ }^{2)}$ observed distortion of the T-loop frequently in decompensated cases with left ventricular hypertrophy. Nimura ${ }^{3)}$ also observed these changes and described 5 types of the T-loop in left ventricular strain. His vectorcardiograms were recorded with Grishman's system but his types I and II correspond to our type 1 and 2, his type III to our type 5, his type IV to our type 6 and his type $\mathrm{V}$ to our type 7 . And also in our cases, these types were frequently observed. Nimura pointed out an increase in number of incompetent patients from type I to V. In our observation, higher percentage of abnormal cases was noticed in hypertension with cardiac complaints (group II) than without them (group I) and the QRS-T angle is larger in types 5,6 and 7 than in normal types, since the direction of the QRS-loop does not differ materially in these types and the T-loop deviates increasingly rightward and then superiorly.

In Fig. 6, several types of the T-loop were described schematically

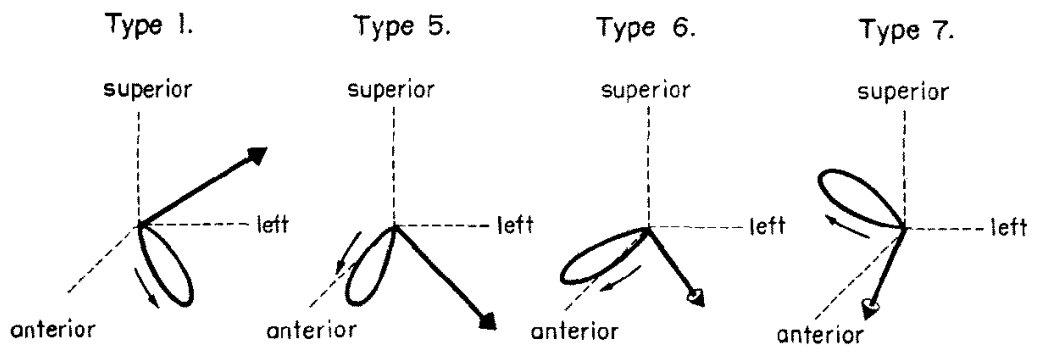

Fig. 6. Schematic description of the T-loop with its polar vector, which was frequently observed in left ventricular hypertrophy (viewed from left anterior direction).

with its polar vector. In this figure, the T-loop changes its direction rightward and then upward from type 1 to type 7 with directional change of its plane. Some relations between orientation and inscription of the loop could be interpreted in terms of the geometrical rule stated above. As far as the T-loop is oriented left, anteriorly and inferiorly as in normal cases, type 5 is not possible according to that rule. The inscription of type 5 could occur after the deviation of the $\mathrm{T}$ axis to right anterior quadrant in horizontal plane. On the other hand, as the inscription of type 1 is allowed for the T-loop of inferior and anterior direction, it is not of geometrical necessity but an empirical fact that in none of the cases with hypertension group I, the T-loop of normal type is directed 
more than $120^{\circ}$ in horizontal plane. In fact, in hypertension group II, almost all directions occur with the T-loop of normal inscription type. These abnormal directions with normal inscription of the T-loop occurred most frequently in cases with anginal attacks. Conversely, normal direction with abnormal inscription was observed in angina pectoris without hypertension (not included in the study group of this report), in right ventricular hypertrophy and in several other conditions.

Some investigators have suggested that the distortion of the T-loop is due to the primary changes of myocardium. However, inscription and orientation of the loop are related to a certain extent, and since the directional change of the T-loop is not necessarily related to the primary changes of myocardium, further investigation should be required to draw a general conclusion.

Right Ventricular Hypertrophy :-

T-loops of types 2, 3 and 7 were frequently observed in mitral stenosis and were described in Fig. 7. In addition to these types, type 6 was observed in some cases with congenital heart disease.

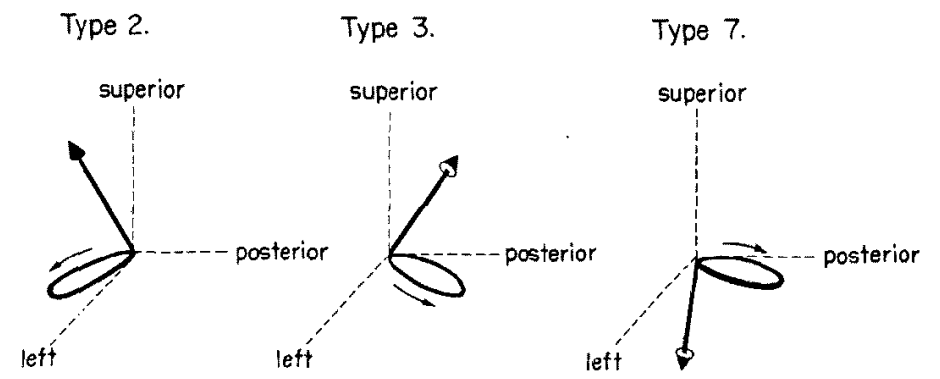

Fig. 7. Schematic description of the T-loop with its polar vector, which was frequently observed in right ventricular hypertrophy (viewed from left posterior direction).

In average, the T-loops of types 2,3 and 7 in mitral stenosis were posteriorly directed increasingly in this order (Fig. 4). But in congenital heart disease, type 7 was not confined to the posteriorly directed T-loop. In 4 cases with atrial septal defect, for example, normally oriented T-loop was of type 7. According to the geometrical rule, type 3 is excluded for leftward, anteriorly and inferiorly directed loop. Both type 3 and type 7 are allowed with the loop of posterior direction. These relations may play a role in determination of types of the T-loop.

Generally speaking, in right ventricular hypertrophy, difference between the directions of the T-loop of various types was not so marked as in left ventricular hypertrophy. There are considerable overlapped cases. 
In this condition, relatively small change in direction was accompanied by change in inscription. The T-loop of normal direction and of abnormal inscription was observed, as stated, in some cases with right ventricular hypertrophy. This is in contrast with left ventricular hypertrophy, in which, after the directional change up to $100^{\circ} \sim 120^{\circ}$ in horizontal plane, the change of inscription follows. On the other hand, in right ventricular hypertrophy, there were many cases with abnormal inscription of the QRS-loop, which was rarely seen in left ventricular hypertrophy. The fact that in all cases with the T-loop of normal inscription types, the QRS-loop was inscribed normally both in mitral stenosis and in congenital heart disease, indicated that the T-loop was more ready to change its inscription than the QRS-loop. These results may be of some value in assessing the severity of conditions.

\section{Summary}

(1) Frank lead vectorcardiogram was recorded in 30 normal persons and in 323 cases with hypertension and acquired and congenital heart disease. The T-loop was classified into 8 types according to the directions of inscription in 3 planar projections. Frequently observed types were examined with the direction of the maximal $\mathrm{T}$ vector.

(2) In majority of normal cases, the T-loop was inscribed counterclockwise in horizontal and clockwise in sagittal planes.

(3) In left ventricular hypertrophy, abnormal inscription of the Tloop was observed with abnormal rightward and superior deviation of its maximal vector and the T-loop oriented more than $120^{\circ}$ in horizontal plane was usually accompanied by abnormal inscription. Percentage of abnormal inscription was higher in cases with cardiac complaints.

(4) In right ventricular hypertrophy, directional change of the Tloop was relatively small but changes in inscription of it were common. The T-loop was always inscribed abnormally in cases with abnormal inscription of the QRS-loop.

(5) The concept of the polar vector was found to be valuable in studying the inscription and the direction of the T-loop. Significance of changes in inscription of the T-loop was discussed.

\section{REFERENCES}

1. Kimura, N. : Jap. Circulat. J. 13: 312, 1949.

2. Portheine, H. : Zschr. f. Kreislaufforsch. 44: 368, 1955. 
3. Nimura, Y.: Am. Heart J. $57: 552,1959$.

4. Karni, H.S.: Am. Heart J. $56: 518,1958$.

5. Burger, H.C. and Vaane, J.P.: Am. Heart J. 56 : 29, 1958.

6. Pipberger, H.V.: Circulation 16: 926, 1957. 